\title{
Kinetics and Dynamics of O + OClO Reaction in a Modified Many-Body Expansion Potential Energy Surface for $\mathrm{ClO}_{3}$
}

O. B. M. TEIXEIRA, J. M. C. MARQUES, A. J. C. VARANDAS

Departamento de Química, Universidade de Coimbra, 3004-535 Coimbra, Portugal

Received 22 September 2006; revised 19 December 2006; accepted 26 January 2007

DOI 10.1002/kin.20257

Published online in Wiley InterScience (www.interscience.wiley.com).

\begin{abstract}
The $\mathrm{ClO}_{3}$ many-body expansion potential energy surface of Farantos and Murrell (Int J Quantum Chem 1978, 14, 659) has been modified along the minimum energy path for the reaction $\mathrm{O}+\mathrm{OClO} \rightarrow \mathrm{ClO}+\mathrm{O}_{2}$ such as to conform with the available kinetics data. The dynamics of the title reaction is also studied for temperatures of relevance in stratospheric chemistry. Two mechanisms for $\mathrm{ClO}+\mathrm{O}_{2}$ formation are identified: (i) direct abstraction of a terminal oxygen atom from the $\mathrm{OClO}$ reactant and (ii) formation of an intermediate $\mathrm{ClO}_{3} \mathrm{Com}$ plex followed by dissociation. The novel potential energy surface gives also a good description of the kinetics of the reaction $\mathrm{Cl}+\mathrm{O}_{3} \rightarrow \mathrm{ClO}+\mathrm{O}_{2}$. (C) 2007 Wiley Periodicals, Inc. Int J Chem Kinet 39: 422-430, 2007
\end{abstract}

\section{INTRODUCTION}

Recently, we have investigated the relevance of vibrationally hot $\mathrm{ClO}+\mathrm{O}_{2}$ collisions in the chemistry of stratospheric ozone [1]. Although the $\mathrm{ClO}+\mathrm{O}_{2}$ reaction was predicted to have a modest role as an ozone source, local thermodynamic disequilibrium (LTD) [2] should be considered when modeling the middle atmosphere as vibrational relaxation of the colliding di-

Correspondence to: A. J. C. Varandas; e-mail: varandas@qtvs1. qui.uc.pt.

Contract grant sponsor: Fundação para a Ciência e a Tecnologia, Portugal.

Contract grant numbers: REEQ/128/QUI/2005, POCI/QUI/ 60501/2004, and POCI/AMB/60261/2004.

(c) 2007 Wiley Periodicals, Inc. atomics is found to be small [1]. This finding supports the measurements of Matsumi et al. [3] who reported a value of $5 \times 10^{-14} \mathrm{~cm}^{3} \mathrm{~s}^{-1}$ for the $\mathrm{ClO}(v=1 \rightarrow 0)$ vibrational relaxation rate constant by collisions with either $\mathrm{N}_{2}$ or Ar. Being about 2 orders of magnitude smaller than our theoretical value [1] for collisions with $\mathrm{O}_{2}$, this experimental result may stress even further the importance of considering LTD when carrying out the above modeling studies.

In addition to $\mathrm{Cl}+\mathrm{O}_{3}$ and $\mathrm{ClO}+\mathrm{O}_{2}$, the $\mathrm{O}+\mathrm{OClO}$ reaction is another important collision process in atmospheric chemistry that evolves on the same $\mathrm{ClO}_{3}$ potential energy surface. In fact, the $\mathrm{OClO}$ species participates both in the ozone depletion chemistry by Freons in the stratosphere [4] and formation of the chlorate radical through the $\mathrm{O}+\mathrm{OClO}$ and 
$\mathrm{XO}+\mathrm{OClO}\left(\mathrm{X}=\mathrm{Cl}, \mathrm{Br}, \mathrm{O}_{2}\right)$ reactions. Experimentally, the $\mathrm{O}+\mathrm{OClO}$ reaction has been investigated by several groups $[5,6]$, with the occurrence of the reaction $\mathrm{O}+\mathrm{OClO} \rightarrow \mathrm{ClO}+\mathrm{O}_{2}$ being confirmed in a detailed low-pressure study by Gleason et al. [6] who estimated the corresponding rate constant to be $1 \times 10^{-13} \mathrm{~cm}^{3} \mathrm{~s}^{-1}$. This result has been corroborated theoretically by Zhu and Lin [7], who found that the concurrent occurrence of both direct abstraction and indirect association/stabilization processes is in agreement with the experimental work [6].

The aim of this work is threefold: (i) to modify the $\mathrm{ClO}_{3}$ many-body expansion (MBE) potential energy surface of Farantos-Murrell such as to mimic the experimental rate constants for the title reaction, (ii) to investigate the importance of the reaction $\mathrm{O}+\mathrm{OClO} \rightarrow \mathrm{ClO}+\mathrm{O}_{2}$ for $\mathrm{O}_{2}$ formation in the high atmosphere, and (iii) to assess the role of the title reaction in maintaining LTD in the stratosphere. The paper is structured as follows. The next section presents the main features of the modified MBE (mMBE) potential energy surface for the title reaction and describes the changes that have been made. The details of the trajectory calculations are reported in Trajectory Calculations, whereas the results are compared with experimental data in Results and Discussion. The last section gathers the conclusions.

\section{POTENTIAL ENERGY SURFACE}

\section{The Many-Body Expansion Form}

The potential energy surface [8] for ground-state $\mathrm{ClO}_{3}$ has been modeled by using the many-body expansion [9] method and shown to be reliable for the description of the major dynamics features and kinetics of the exoergic $\mathrm{Cl}+\mathrm{O}_{3}$ reaction $[1,8]$ over the temperature range $200 \leq T(K) \leq 600$. It shows a small energy barrier of $\sim 0.3 \mathrm{kcal} \mathrm{mol}^{-1}$ and has been recently applied in our trajectory study of the reverse $\mathrm{ClO}+\mathrm{O}_{2}$ reaction at stratospheric temperatures [1]. Although the use of a single-valued form to study the $\mathrm{ClO}_{3}$ system may show limitations (in the sense that it cannot account for the influence of other electronic states), the global modeling of a single-sheeted form from sufficiently accurate ab initio calculations is a formidable task even for just the ground-electronic state of $\mathrm{ClO}_{3}$.

The accuracy of the $\mathrm{MBE} \mathrm{ClO}_{3}$ potential energy surface has not been tested thus far for studying the reaction $\mathrm{O}+\mathrm{OClO} \rightarrow \mathrm{ClO}+\mathrm{O}_{2}$. Since it has been calibrated to reproduce only the main energetic features of the $\mathrm{Cl}+\mathrm{O}_{3}$ ozone-depletion reaction, there is no warranty that it will also give acceptable results for the title reaction. Figure 1 shows the two $\mathrm{O}+\mathrm{OClO}$ reac- tion paths of this MBE potential energy surface (only the major structures are shown): path (i) leads to formation of the intermediate $\mathrm{ClO}_{3}$ complex through the transition state TS1 (which is preceded by the van der Waals minimum, vdW1), followed by dissociation into $\mathrm{ClO}+\mathrm{O}_{2}$ over the TS3 barrier; path (ii) corresponds to direct abstraction of an oxygen atom by overcoming TS2. This path leads to a weakly bound structure (referred heretofore as a van der Waals structure, vdW2) followed by a transition state (TS4), immediately before formation of the $\mathrm{ClO}+\mathrm{O}_{2}$ products. The major features of all involved structures are given in Table 1. As shown in Fig. 1 and Table 1, path (ii) is barrierless in the MBE potential energy surface. Moreover, all its saddle points but TS3 lie below the $\mathrm{O}+\mathrm{OClO}$ dissociation asymptote, and hence there is no barrier for formation of the $\mathrm{ClO}_{3}$ complex or direct abstraction reactions. As it will be shown later, the lack of potential barriers for the $(\mathrm{O}+\mathrm{OClO})$ approaching reactants leads to a gross overestimation of reactivity, in clear disagreement with available experimental $[5,6]$ rate constant measurements over the temperature range $200 \leq T(K) \leq 450$.

\section{Modified Many-Body Expansion Potential Energy Surface}

A major goal of the present work is to modify the $\mathrm{MBE} \mathrm{ClO}_{3}$ potential energy surface such as to account for the experimental $[5,6]$ rate constants of the reaction $\mathrm{O}+\mathrm{OClO} \rightarrow \mathrm{ClO}+\mathrm{O}_{2}$ (over the temperature range of relevance in atmospheric chemistry), without spoiling the good agreement obtained for the $\mathrm{Cl}+\mathrm{O}_{3}$ reaction. A simple way to accomplish this goal is by adding Gaussian functions to introduce appropriate barriers. The mMBE potential energy surface so obtained assumes the following form:

$$
\begin{aligned}
V_{\mathrm{ClO}_{3}}(\mathbf{R})= & V_{\mathrm{MBE}}(\mathbf{R})+\sum_{i=1}^{3} A_{i} \\
& \times \exp \left[-\gamma_{i}\left(\sum_{j=1}^{6} R_{j}-P_{i}^{0}\right)^{2}\right] f_{i} \\
& +\sum_{i=4}^{5} A_{i} \exp \left[-\gamma_{i} \sum_{j=1}^{3}\left(R_{j}-R_{j}^{0}\right)^{2}\right. \\
& \left.-\gamma_{i}^{\prime} \sum_{j=1}^{3}\left(\theta_{j}-\theta_{j}^{0}\right)^{2}\right]
\end{aligned}
$$

where $V_{\mathrm{MBE}}(\mathbf{R})$ is the MBE potential energy surface; $\mathbf{R}$ is the vector of the six internuclear coordinates 


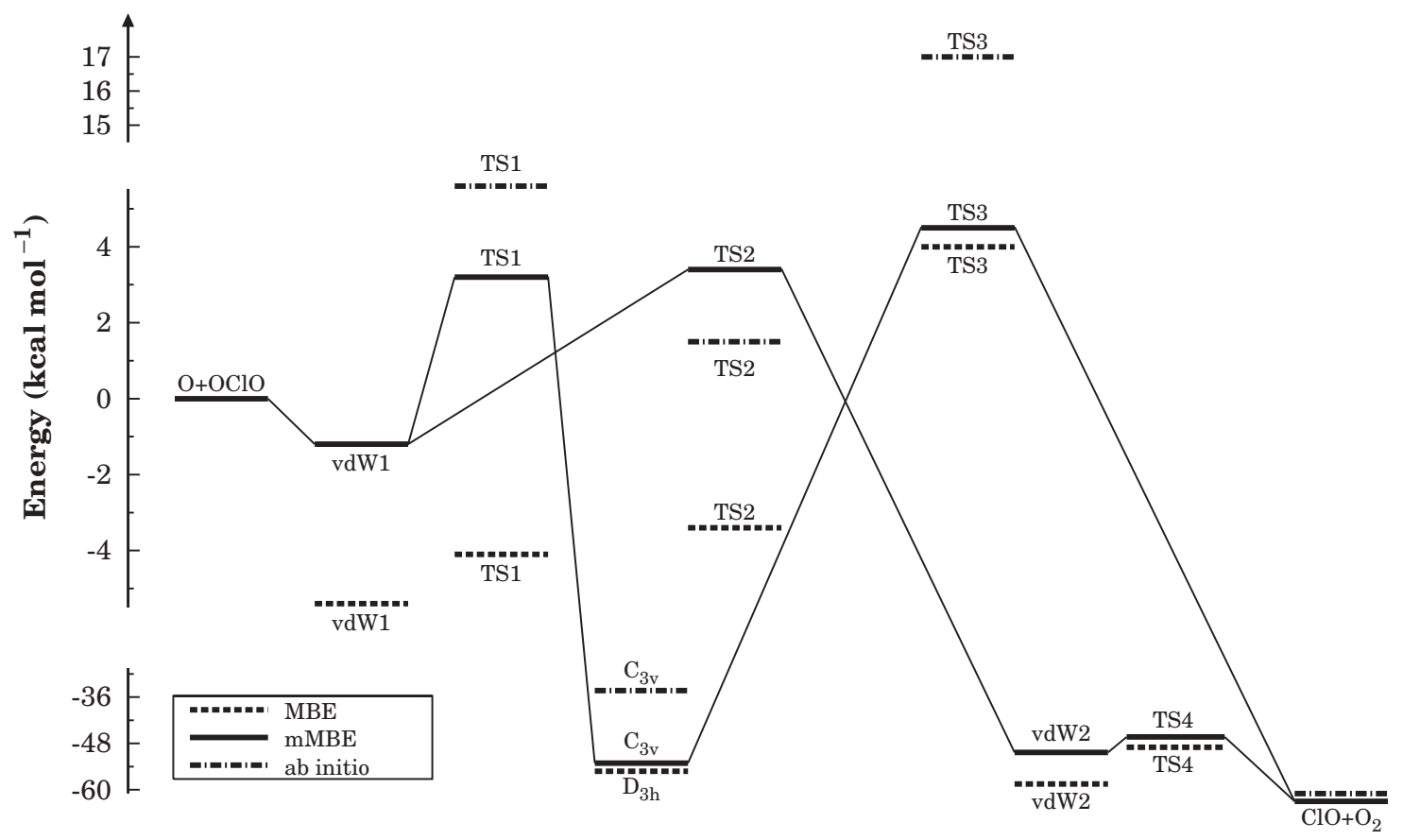

Figure 1 Schematic diagram of the energetics for the reaction $\mathrm{O}+\mathrm{OClO} \rightarrow \mathrm{ClO}+\mathrm{O}_{2}$ in the $\mathrm{MBE}[8]$ and mMBE potential energy surfaces, and from the ab initio calculations of Zhu and Lin [7]. The thick solid lines correspond to the TS1, TS2, TS3, and TS4 saddle points and vdW1, and vdW2 van der Waals minima in the mMBE form of the present work, whereas the dashed and the dashed-dotted ones are, respectively, for the MBE potential and the ab initio calculations. Energies are in $\mathrm{kcal} \mathrm{mol}^{-1}$, with the zero of energy at the $\mathrm{O}+\mathrm{OClO}$ asymptote.

$\left[R_{j}(j=1, \ldots, 6)\right] ; A_{i}, \gamma_{i}$, and $P_{i}^{0}$ are parameters that are numerically defined in Table II, $R_{1}^{0}=R_{2}^{0}=R_{3}^{0}=$ $1.478 \AA$ is a reference geometry that is kept identical for Gaussians numbers 4 and 5 ; and $\theta_{j}^{0}(j=1-3)$ are reference angles given in Table II. The damping functions $f_{i}$ have been chosen as

$$
\begin{gathered}
f_{1}\left(R_{1}, R_{2}, R_{3}\right)=\exp \left[-a_{1}\left(\sum_{k=1}^{3} R_{k}-R_{\Sigma}\right)^{2}\right] \\
f_{3}\left(\theta_{1}, \theta_{2}, \theta_{3}\right)=\exp \left[-a_{3}\left(\sum_{k=1}^{3} \theta_{k}-\theta_{\Sigma}\right)^{2}\right]
\end{gathered}
$$

with $f_{2}=1, a_{1}=0.2 \AA^{-2}, a_{3}=0.2 \mathrm{rad}^{-2}, R_{\Sigma}=$ $6.28388 \AA$, and $\theta_{\Sigma}=5.61647 \mathrm{rad}$. We emphasize the use of valence coordinates for the fitting procedure as recently recommended [10] for the $\mathrm{N}_{2} \mathrm{H}_{2}$ system, and the fact that the damping function $f_{1}$ has been calibrated such as to leave essentially unaltered the original barrier for the $\mathrm{Cl}+\mathrm{O}_{3}$ reaction. In turn, $f_{3}$ has been chosen to ensure that the Gaussian centered at the TS3 region has no major impact on TS1. Finally, the last summation in Eq. (1) corrects the MBE form to give a $\mathrm{ClO}_{3}$ minimum structure (and corresponding energetics) in closer agreement with experiment [1113]. This is clear from the contour plot of Fig. 2, which shows that the $\mathrm{ClO}_{3}$ minimum has $\mathrm{C}_{3 \mathrm{v}}$ symmetry in the mMBE form (in contrast with $\mathrm{D}_{3 \mathrm{~h}}$ for MBE) with a well depth of $-53.1 \mathrm{kcal} \mathrm{mol}^{-1}$; for a comparison, see Table I. Note also from Fig. 2 that the $\mathrm{ClO}_{3}$ minimum has a pyramid shape with the angle $\beta=112^{\circ}$, with the $\mathrm{D}_{3 \mathrm{~h}}$ structure becoming now the saddle point for the umbrella inversion. Concerning other structures relevant for the dynamics of the title reaction, the mMBE potential energy surface shows an increase in the energy barriers for transition states TS1, TS2, and TS3 and a decrease in well depth of the vdW1 van der Waals minimum. Table I shows that the transition states TS1 and TS2 are, in contrast with the original MBE function, 3.3 and $3.4 \mathrm{kcal} \mathrm{mol}^{-1}$ above the $\mathrm{O}+\mathrm{OClO}$ asymptote, as indicated by the thick solid lines in Fig. 1. Other relevant features of the original MBE form are, at most, only modestly altered (e.g., TS3 increases from $4.0 \mathrm{kcal} \mathrm{mol}^{-1}$ in MBE to $4.8 \mathrm{kcal} \mathrm{mol}^{-1}$ in mMBE). Note further that the energy difference between vdW2 and TS4 structures diminishes from $7.0 \mathrm{kcal} \mathrm{mol}^{-1}$ in MBE to $4.0 \mathrm{kcal} \mathrm{mol}^{-1}$ in mMBE. Although hard to justify in the absence of accurate electronic structure calculations, such a structure can tentatively be 


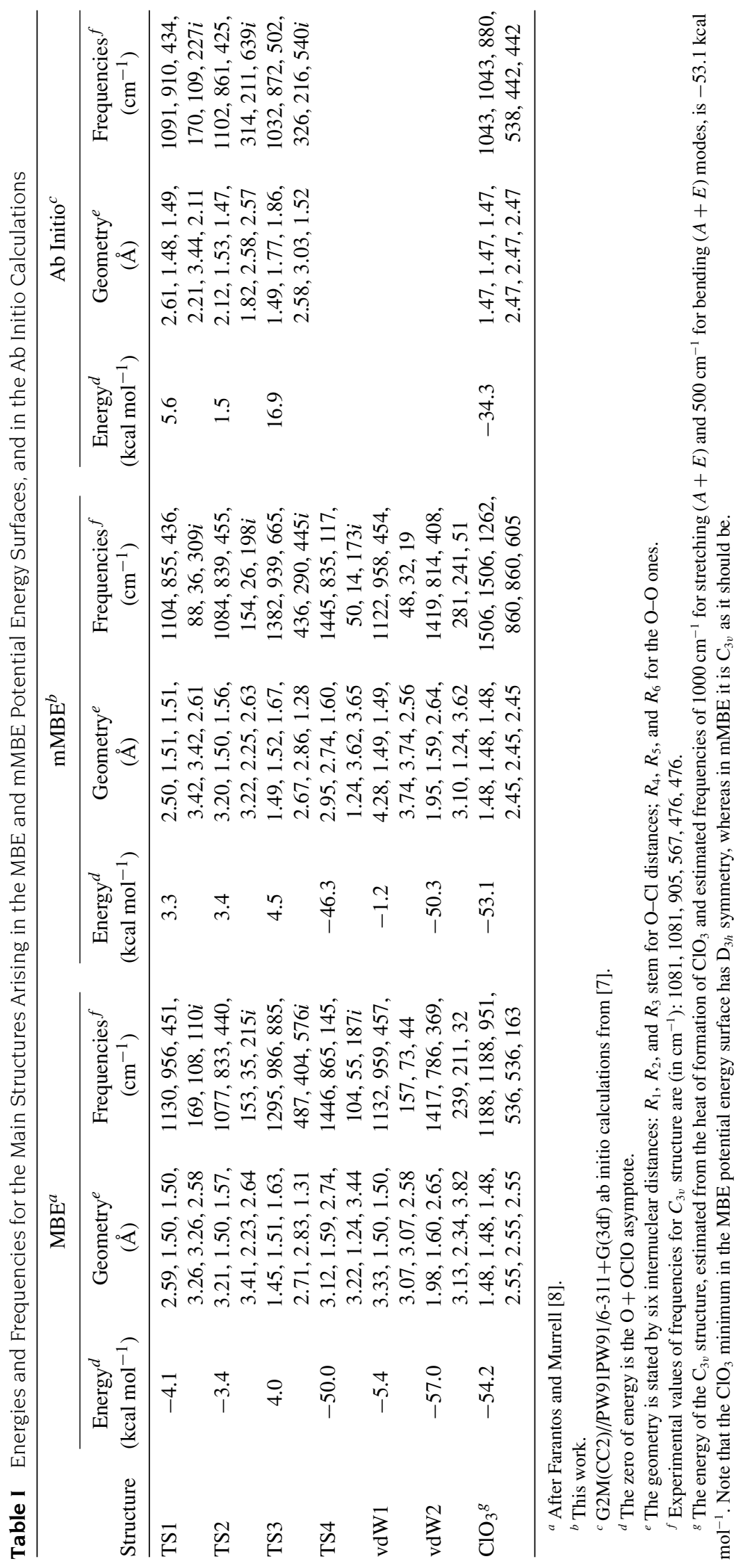


Table II Parameters Defining the Gaussian Functions in Eq. (1). See the text

\begin{tabular}{lccccccc}
\hline Gaussian Function & $A\left(\mathrm{kcal} \mathrm{mol}^{-1}\right)$ & $\gamma\left(\AA^{-2}\right)$ & $P^{0}(\AA)$ & $\gamma^{\prime}\left(\mathrm{rad}^{-2}\right)$ & $\theta_{1}^{0}(\mathrm{rad})$ & $\theta_{2}^{0}(\mathrm{rad})$ & $\theta_{3}^{0}(\mathrm{rad})$ \\
\hline 1 & 4.843 & 0.15 & 14.78 & n.r. & n.r. & n.r. & n.r. \\
2 & 9.741 & 0.50 & 11.81 & n.r. & n.r. & n.r. & n.r. \\
3 & 2.998 & 2.00 & 14.74 & n.r. & n.r. & n.r. & n.r. \\
4 & -26.928 & 20.00 & n.r. & 11.25 & 1.88 & 1.88 & 1.88 \\
5 & 5.100 & 20.00 & n.r. & 15.00 & 2.09 & 2.09 & 2.09 \\
\hline
\end{tabular}

${ }^{a}$ n.r. $=$ Not relevant.

rationalized as due to the leading electrostatic interaction between the permanent dipole moment of $\mathrm{ClO}$ and the permanent quadrupole moment of $\mathrm{O}_{2}$ in a way similar to the $1: 1$ complex $[14,15]$ involving $\mathrm{O}_{2}$ and $\mathrm{OH}$.

\section{TRAJECTORY CALCULATIONS}

The trajectory study reported in the present work covers temperatures over the range $250 \leq T(\mathrm{~K}) \leq 500$ using both the original $\mathrm{ClO}_{3} \mathrm{MBE}$ and $\mathrm{mMBE}$ potential energy surfaces (see the section Potential Energy Surface). A total of $1.1 \times 10^{5}$ trajectories have been run $\left(10^{4}\right.$ trajectories for each temperature but $T=250,263$ $\mathrm{K}$, where the numbers are $4 \times 10^{4}$ and $3 \times 10^{4}$, respectively) for the mMBE potential energy surface by using an extensively adapted version $[1,16]$ of the VENUS96 computer code [17]; for the MBE one, batches of $2 \times 10^{3}$ trajectories have been run at $T=250,300$, 400 , and $500 \mathrm{~K}$. The integration time step used in the trajectory calculations was $0.01 \mathrm{fs}$, which is sufficient to conserve total energy within $10^{-4} \mathrm{kcal} \mathrm{mol}^{-1}$.

The initial conditions for the trajectory calculations have been established as follows: The collision energy $\left(E_{\mathrm{tr}}\right)$ was selected from a Maxwell-Boltzmann distribution using the cumulative function [18]

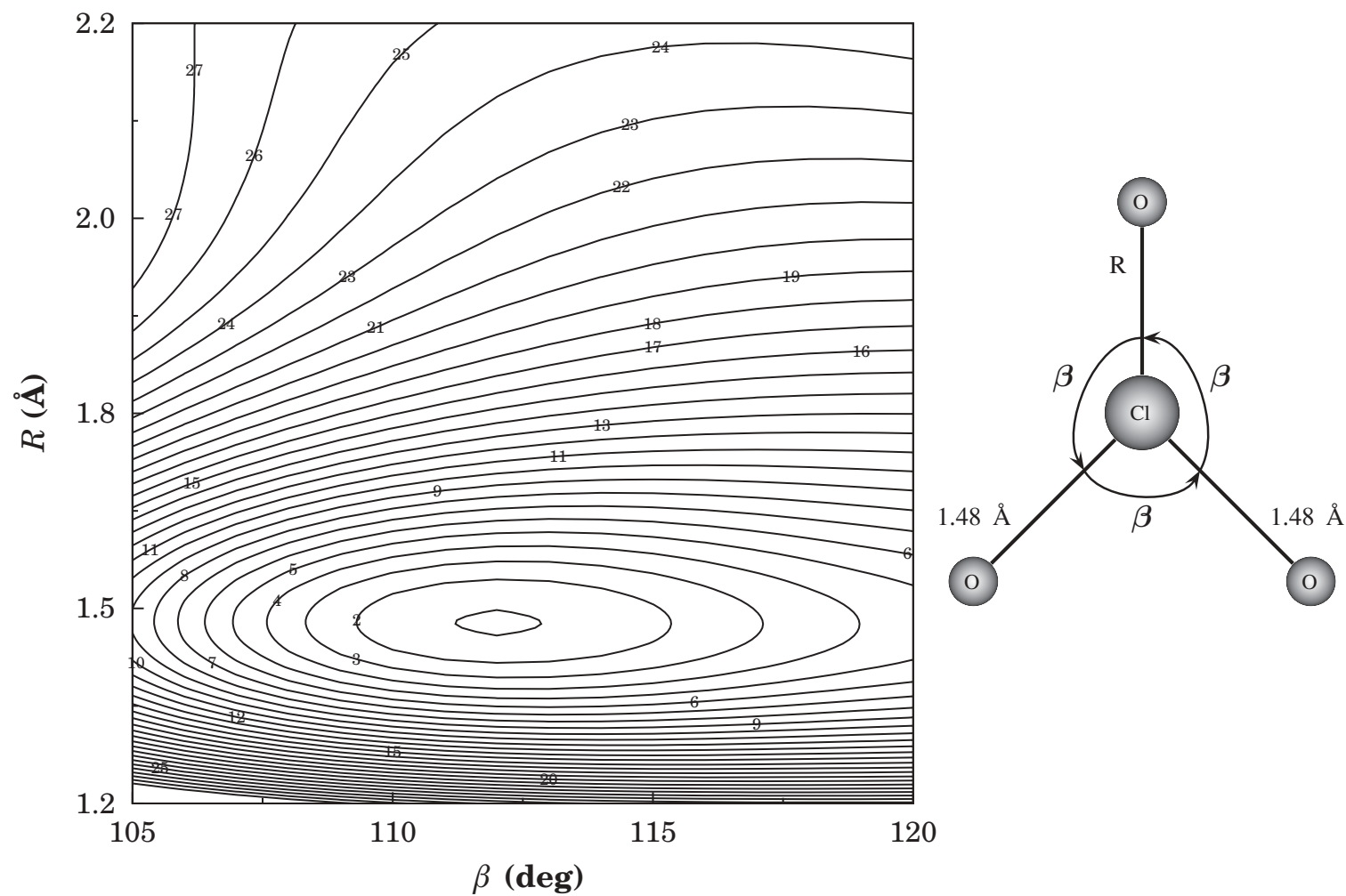

Figure 2 Energy-contour plot for the mMBE potential energy surface showing the $C_{3 v}$ symmetry of the $\mathrm{ClO}_{3}$ structure. The contours are equally spaced by $2.3 \mathrm{kcal} \mathrm{mol}^{-1}$, starting at $-52.9 \mathrm{kcal} \mathrm{mol}^{-1}$ below the $\mathrm{O}+\mathrm{OClO}$ asymptotic limit. For the coordinates, see plot on the right-hand side of the panel. 


$$
G\left(E_{\mathrm{tr}}\right)=\left(\frac{1}{k_{\mathrm{b}} T}\right)^{2} \int_{0}^{E_{\mathrm{tr}}} E_{\mathrm{tr}}^{\prime} \exp \left(-E_{\mathrm{tr}}^{\prime} / k_{b} T\right) \mathrm{d} E_{\mathrm{tr}}^{\prime}
$$

where the value of $E_{\text {tr }}$ for each trajectory is randomly calculated by solving numerically the equation $G\left(E_{\mathrm{tr}}\right)-\xi=0$ ( $\xi$ is a random number). In turn, the assignment of the $\mathrm{OClO}$ vibrational energy has been done by performing a fixed normal mode energy sampling [17]; the $\mathrm{OClO}$ vibrational energy was fixed at the corresponding zero-point value. A rotational energy of $R T / 2$ ( $R$ is the gas constant) has been put on each axis of inertia in accordance with the equipartition principle.

For every reactive trajectory, the rotational states of the products have been assigned as in [1]. In addition, the final vibrational quantum number $\left(v_{f}\right)$ has been calculated by using $j$ and the semiclassical quantization followed by rounding-off the calculated real value to its nearest integer. Finally, the thermal rate constants have been calculated by using

$$
k(T)=g_{e}(T)\left(\frac{8 k_{\mathrm{b}} T}{\pi \mu_{\mathrm{O}-\mathrm{OCIO}}}\right)^{1 / 2} \sigma_{r}(T)
$$

where $k_{\mathrm{b}}$ is the Boltzmann constant, $\mu_{\mathrm{O}-\mathrm{OClO}}$ is the atom-triatom reduced mass, and the electronicdegeneracy factor is $g_{e}(T)=2 /\{2[5+$ $3 \exp (-228 / T)+\exp (-326 / T)]\}$. As usual, the temperature-dependent reactive cross sections are calculated from the expression $\sigma_{r}(T)=$ $\pi b_{\max }^{2} \frac{N_{\mathrm{ClO}+\mathrm{O}_{2}}(T)}{N(T)}$, and the $68 \%$ standard deviations arising from the Monte-Carlo averaging determined from $\Delta \sigma_{r}(T)=\sigma_{r}(T)\left[\frac{N(T)-N_{\mathrm{ClO}+\mathrm{O}_{2}}(T)}{N(T) N_{\mathrm{ClO}+\mathrm{O}_{2}}(T)}\right]^{1 / 2}$, where $N(T)$ is the total number of trajectories, and $N_{\mathrm{ClO}+\mathrm{O}_{2}}(T)$ the corresponding number of events forming $\mathrm{ClO}+\mathrm{O}_{2}$ products.

\section{RESULTS AND DISCUSSION}

The main trajectory results for both MBE (values in brackets) and mMBE potential energy surfaces are given in Table III. This shows that the $\mathrm{O}+\mathrm{OClO}$ reactive cross sections for the mMBE potential energy surface are always nearly 3 orders of magnitude smaller than those calculated from the MBE function; note also the huge differences between the corresponding maximum impact parameters $\left(b_{\max }\right)$. This result can be explained by inspection of Fig. 3, which shows the minimum energy paths for direct abstraction of an oxygen atom and $\mathrm{ClO}_{3}$ formation. These show that the title reaction occurs without a barrier in the MBE potential energy surface, whereas in mMBE there are barriers for both such processes. In fact, one expects that the title reaction may proceed by two mechanisms: (i) direct abstraction of an oxygen atom via TS2; (ii) formation of the $\mathrm{ClO}_{3}$ via TS1, followed by dissociation. Recently, Zhu and Lin [7] advocated from a GAUSSIAN2 (G2M) study (denoted G2M(CC2)//PW91/6$311+\mathrm{G}(3 \mathrm{df}))$ of the title reaction that $\mathrm{ClO}_{3}$ dissociation cannot occur by overcoming TS3 because this is higher in energy than both TS1 and TS2 as it involves the breaking of two bonds. Although the energy differences between TS1, TS2, and TS3 are (in the mMBE potential energy surface) not as high as in their own calculations, the process of breaking simultaneously two bonds is still a dynamical bottleneck. Thus, it is likely that the formed $\mathrm{ClO}_{3}$ complexes cross over TS1 back to the vdW1 region and finally evolve via TS2 and TS4 to yield $\mathrm{ClO}+\mathrm{O}_{2}$. In fact, a detailed inspection at $T=300 \mathrm{~K}$ revealed that only $\sim 30 \%(\sim 9 \%)$ of the reactive trajectories in the $\mathrm{mMBE}$ (MBE) potential energy surface follow a direct-type mechanism, i.e., oxygen abstraction, with the remaining trajectories leading to formation of a $\mathrm{ClO}_{3}$ complex that subsequently dissociates to form $\mathrm{ClO}+\mathrm{O}_{2}$. The disparity

Table III Results of the Trajectory Calculations for the Reaction $\mathrm{O}+\mathrm{OClO} \rightarrow \mathrm{ClO}+\mathrm{O}_{2}$ Evolving on the mMBE Potential Energy Surface from the Present Work

\begin{tabular}{lcccc}
\hline$T(\mathrm{~K})$ & $b_{\max }(\AA)$ & $N_{\mathrm{ClO}+\mathrm{O}_{2}}$ & $\sigma_{r} \pm \Delta \sigma_{r}\left(\AA^{2}\right)$ & $k^{a}\left(10^{-13} \mathrm{~cm}^{3} \mathrm{~s}^{-1}\right)$ \\
\hline 250 & $3.5(7.5)$ & $21(597)$ & $0.02 \pm 0.001(53.0 \pm 0.6)$ & $0.20 \pm 0.04(523 \pm 17)$ \\
263 & 3.5 & 31 & $0.04 \pm 0.002$ & $0.40 \pm 0.07$ \\
300 & $3.5(8.0)$ & $20(464)$ & $0.08 \pm 0.005(46.9 \pm 0.6)$ & $0.80 \pm 0.18(487 \pm 20)$ \\
345 & 3.5 & 33 & $0.127 \pm 0.007$ & $1.37 \pm 0.24$ \\
400 & $4.0(8.0)$ & $41(411)$ & $0.20 \pm 0.01(41.4 \pm 0.6)$ & $2.33 \pm 0.37(469 \pm 19)$ \\
500 & $4.0(7.5)$ & $88(394)$ & $0.44 \pm 0.01(34.9 \pm 0.5)$ & $5.39 \pm 0.57(425 \pm 25)$ \\
\hline
\end{tabular}

Given in parenthesis, for some energies, are the corresponding values obtained using the MBE one.

${ }^{a}$ Calculated by using Eq. (5). 


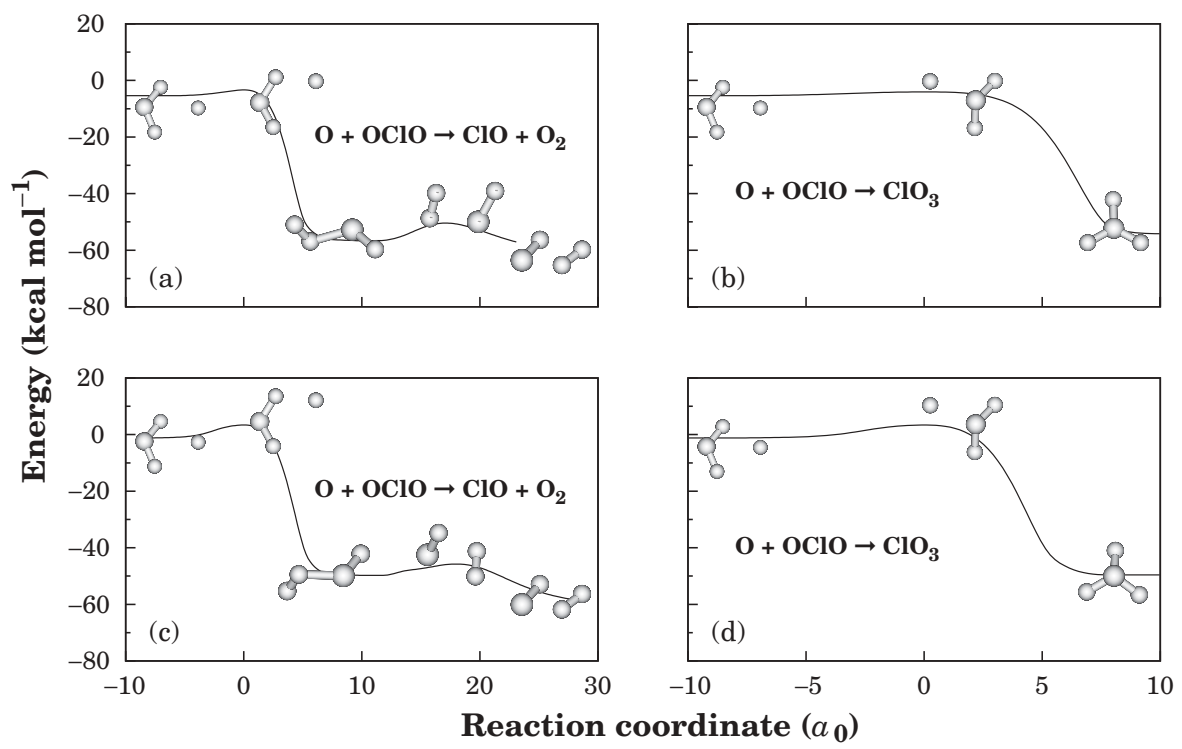

Figure 3 Minimum energy paths for the MBE (panels (a) and (b)) and mMBE (panels (c) and (d)) potential energy surfaces: (a) and (c) path connecting the van der Waals minimum vdW1 to the $\mathrm{ClO}+\mathrm{O}_{2}$ products via TS2 and passing through vdW2 and TS4; (b) and (d) path connecting the van der Waals minimum vdW1 and the $\mathrm{ClO}_{3}$ minimum via TS1.

of the results in the MBE and mMBE potential energy surfaces may be explained by the differences in the minimum energy paths for formation of $\mathrm{ClO}_{3}$ shown in Figs. 3(b) and 3(d). Note that the predominance of the mechanism based on the decomposition of $\mathrm{a} \mathrm{ClO}_{3}$ intermediate complex rather than a direct abstraction finds support in the flash photolysis-atomic resonance fluorescence measurements of Colussi et al. [5] for the title reaction under stratospheric conditions.

Another important piece of data that helps understanding the mechanism of the title reaction is the vibrational quantum number distributions, $P(v)$, for both $\mathrm{ClO}$ and $\mathrm{O}_{2}$ product molecules. These are shown in Fig. 4 for $T=250$ and $500 \mathrm{~K}$. It is apparent that the $\mathrm{ClO}$ product arises vibrationally colder than $\mathrm{O}_{2}$, especially at low temperatures. For $T=250 \mathrm{~K}$ (Fig. 4(a)), $P(v)$ for $\mathrm{ClO}$ peaks at $v=0$ and extends up to $v=6$, while the corresponding $\mathrm{O}_{2}$ distribution attains its maximum value at $v=12$ and varies from $v=5$ up to $v=14$. In turn, the vibrational quantum number distributions tend to broaden for both $\mathrm{ClO}$ and $\mathrm{O}_{2}$ with increasing temperature, favoring excitation of $\mathrm{ClO}$ versus de-excitation of $\mathrm{O}_{2}$. For $T=500 \mathrm{~K}$ (Fig. 4(b)), $P(v)$ for $\mathrm{ClO}$ extends now up to $v=8$, while the maximum of $P(v)$ for $\mathrm{O}_{2}$ occurs at $v=11$ (with a smaller probability) and extends down to $v=3$. Thus, the title reaction contributes to formation of vibrationally excited species (especially $\mathrm{O}_{2}$ ) in the stratosphere, reinforcing the need to consider LTD when modeling the chemistry of the middle atmosphere [2,19]. As observed [1] for the reaction $\mathrm{Cl}+\mathrm{O}_{3} \rightarrow \mathrm{ClO}+\mathrm{O}_{2}$, the present distribu- tions for $\mathrm{O}+\mathrm{OClO} \rightarrow \mathrm{ClO}+\mathrm{O}_{2}$ are typical of highly exothermic reactions, where one of the bonds $(\mathrm{ClO}$ for the title reaction) is spectator-like $[8,20]$. Of course, the $\mathrm{ClO}$ product molecules arise more excited in the title reaction than was observed in $[1,8,20]$ for the $\mathrm{O}_{2}$

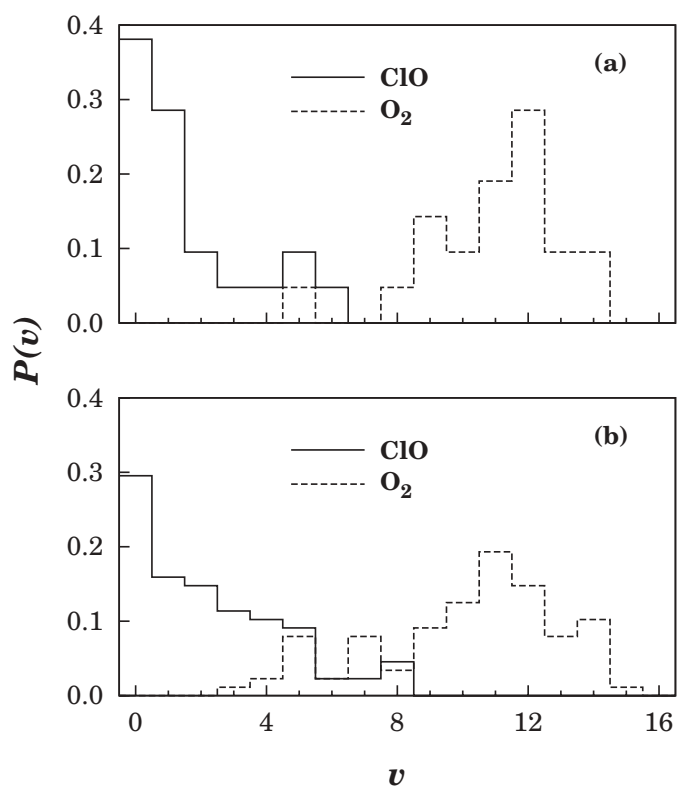

Figure 4 Products vibrational quantum number distributions for $\mathrm{ClO}$ (full lines) and $\mathrm{O}_{2}$ (dashed lines) molecules in the mMBE potential energy surface: (a) $T=250 \mathrm{~K}$ and (b) $T=500 \mathrm{~K}$. 
product (this is the spectator bond in the $\mathrm{Cl}+\mathrm{O}_{3}[1,8]$ and $\mathrm{O}+\mathrm{O}_{3}$ [20] reactions). Although this may partly be attributed to the higher density of vibrational states in $\mathrm{ClO}$, it also reflects the fact that the $\mathrm{O}+\mathrm{OClO}$ trajectories evolve largely through formation of a $\mathrm{ClO}_{3}$ complex (where energy exchange occurs), whereas the $\mathrm{Cl}+\mathrm{O}_{3}$ and $\mathrm{O}+\mathrm{O}_{3}$ reactions follow a direct-type (oxygen abstraction) mechanism $[1,8,20]$.

The calculated thermal rate constants are also shown in Table III (the corresponding values for the MBE potential energy surface are given in parenthesis). The magnitude of the rate constants from the mMBE potential energy surface is predicted to vary from $0.2 \times 10^{-13} \mathrm{~cm}^{3} \mathrm{~s}^{-1}$ at $T=250 \mathrm{~K}$ to $5.39 \times 10^{-13} \mathrm{~cm}^{3} \mathrm{~s}^{-1}$ at $T=500 \mathrm{~K}$, with the whole set of calculated values being well fitted by the Arrhenius form $k(T)=A \exp (-B / T)$, where $A=1.18_{-0.30}^{+0.40} \times$ $10^{-11} \mathrm{~cm}^{3} \mathrm{~s}^{-1}$ and $B=1540.5 \pm 92.8 \mathrm{~K}^{-1}$. Thus, the rate constant for $\mathrm{O}_{2}$ formation by the title reaction is small under the conditions of relevance in the high atmosphere, especially when compared with the thermal rate constants for the reaction $\mathrm{Cl}+\mathrm{O}_{3} \rightarrow \mathrm{ClO}+\mathrm{O}_{2}$ (e.g., $1.34 \times 10^{-11} \mathrm{~cm}^{3} \mathrm{~s}^{-1}$ at $T=300 \mathrm{~K}$ ), either obtained from trajectory calculations [8] or experiment [21-24]. In turn, Fig. 5 allows a comparison between the trajectory results obtained from the present work both with the available experimental results [5,6] and VTST/RRKM calculations [7]. Since experimentalists measure the joint rate constant for both the title reaction and the association process (i.e., $\mathrm{O}+\mathrm{OClO}(+\mathrm{M}) \rightarrow \mathrm{ClO}_{3}(+\mathrm{M}), \mathrm{M}$ being a species that removes the excess of energy), a fair comparison between theory and experiment may have to take this into account. Thus, we have estimated the joint thermal rate constant (open squares in Fig. 5) by adding the QCT

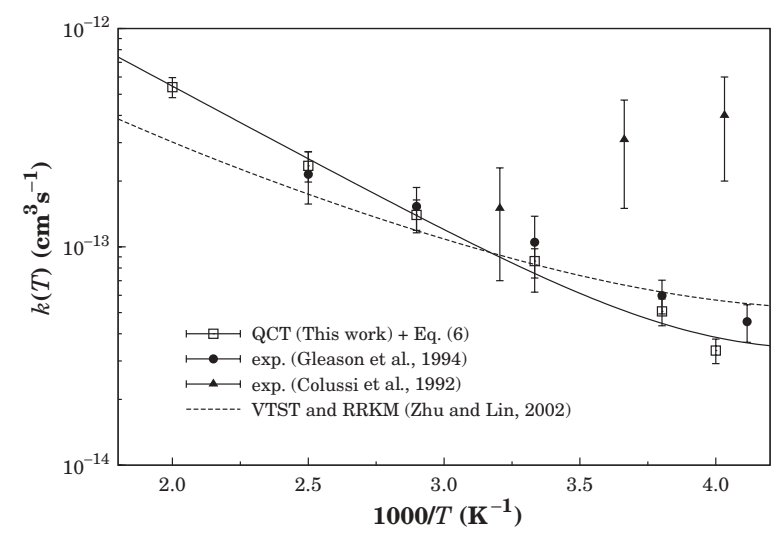

Figure 5 Thermal rate constant for the title reaction: solid line, QCT calculations from the present work, including Eq. (6); dashed line, VTST/RRKM [7]. Key for experimental results: triangles [5]; open circles [6]. See also the text. values of Table III to the association ones given by [7]

$$
k_{\mathrm{ass}}=40.1 T^{-6.16} \exp (-403 / T)
$$

whose influence essentially manifests at low temperatures. Besides $T=250 \mathrm{~K}$, where the statistically based association rate constant of Eq. (6) has a large contribution, the theoretical values of the present work show an excellent agreement with the experimental results of Gleason et al. [6], which have been obtained in a discharge flow system at low pressures (1-5 Torr). Conversely, they are inconsistent with the values of Colussi et al. [5], which have been extrapolated from their high-pressure measurements. The rate constants calculated with the mMBE potential energy surface are also in agreement with the recent theoretical calculations of Zhu and Lin [7] who have utilized VTST and RRKM theories. Note, however, that the calculations performed by Zhu and Lin [7] use their own G2M(CC2)//PW91PW91/6-311+G(3df) points along the minimum energy paths, and hence do not test globally the $\mathrm{ClO}_{3}$ potential energy surface. We further note that discrepancies with experiment are shared by both the G2M(CC2)//PW91/6-311+G(3df) calculations [7] and the present mMBE potential energy surface (see Table I and Fig. 1). For example, the mMBE well depth associated with the $C_{3 v}$ minimum structure of $\mathrm{ClO}_{3}$ coincides with the value of $-53.1 \mathrm{kcal} \mathrm{mol}^{-1}$, which is deduced from experiment (see Table I), whereas the corresponding value by $\mathrm{Zhu}$ and Lin [7] that has been obtained from G2M(CC2)//PW91PW91/6$311+\mathrm{G}(3 \mathrm{df})$ calculations is smaller by about $19 \mathrm{kcal}$ $\mathrm{mol}^{-1}$; in contrast, their calculated frequencies are in closer agreement with experiment than those from the present work. Of course, the importance of the discrepancies between our mMBE potential and the G2M results displayed in Fig. 1 and Table I can only be gaged when state-of-the-art ab initio calculations become available for the whole $\mathrm{ClO}_{3}$ potential energy surface. Another observation goes to the fact that our QCT results slightly exceed the VTST and RRKM ones of Zhu and Lin for temperatures up to $315 \mathrm{~K}$, becoming smaller for larger temperatures. This would seem to violate the well-known fact that the VTST rate is expected to be an upper bound of the classical trajectory one (for a recent discussion concerning transition-state theory that addresses earlier work, see [25]). However, this should cause no surprise as the two calculations employ different potential energy surfaces and hence bear no relation to each other. Finally, we emphasize that the mMBE potential energy surface leaves essentially unaltered our previously reported [1] results for the reaction $\mathrm{Cl}+\mathrm{O}_{3} \rightarrow \mathrm{ClO}+\mathrm{O}_{2}$. Unavoidably, differences may occur in the $\mathrm{ClO}\left(v^{\prime}, j^{\prime}\right)+\mathrm{O}_{2}\left(v^{\prime \prime}, j^{\prime \prime}\right)$ 
reactive and inelastic processes as the trajectories may sample regions of configuration space that suffered alterations with respect to the original MBE form. However, there is at present no experimental data on such processes, and hence such calculations could hardly be used as criteria for the mMBE calibration procedure.

\section{CONCLUSIONS}

Trajectories were run for the reaction $\mathrm{O}+\mathrm{OClO} \rightarrow \mathrm{ClO}+\mathrm{O}_{2}$ over the temperature range $250 \leq T(\mathrm{~K}) \leq 500$. Although the $\mathrm{ClO}_{3} \mathrm{MBE}$ potential energy surface revealed itself inadequate for such a study, we have shown that it could be modified in a simple way to bring the calculated and experimental rate constants into good agreement over the covered range of temperatures, both for the title and $\mathrm{Cl}+\mathrm{O}_{3}$ [1] reactions. Of course, this is a first step toward the construction of an accurate potential energy surface for $\mathrm{ClO}_{3}$, and hence state-of-the-art electronic structure calculations would be valuable for testing and improving the topographical details of the mMBE potential energy surface here reported. This will hopefully be addressed in future work.

O. B. M. Teixeira thanks the Ministério dos Negócios Estrangeiros, Instituto Português de Apoio ao Desenvolvimento, Portugal, for a studentship. He also thanks the Ministério da Educação e Desporto, Direcção Geral do Ensino Superior e Ciência, Cabo Verde, for allowing his studies abroad.

\section{BIBLIOGRAPHY}

1. Teixeira, O. B. M.; Marques, J. M. C.; Varandas, A. J. C. Phys Chem Chem Phys 2004, 6, 2179.

2. Varandas, A. J. C. J Phys Chem A 2004, 108, 758.
3. Matsumi, Y.; Nomura, S.; Kawasaki, M. J Phys Chem 1996, 100, 176.

4. Molina, M. J.; Colussi, A.; Molina, L. T.; Schindler, R. N.; Tso, T. Chem Phys Lett 1990, 173, 310.

5. Colussi, A.; Sander, S. P.; Friedl, R. R. J Phys Chem 1992, 96, 4442.

6. Gleason, J. F.; Nesbitt, F. L.; Stief, L. J. J Phys Chem 1994, 98, 126.

7. Zhu, R. S.; Lin, M. C. J Phys Chem A 2002, 106, 8386.

8. Farantos, S. C.; Murrell, J. N. Int J Quantum Chem 1978, $14,659$.

9. Murrell, J. N.; Carter, S.; Farantos, S. C.; Huxley, P.; Varandas, A. J. C. Molecular Potential Energy Functions; Wiley: Chichester, UK, 1984.

10. Varandas, A. J. C.; Bicsysko, M.; Poveda, L. A. To be published.

11. Atkins, P. W.; Symons, M. C. R. Structure of Inorganic Radicals; Elsevier: Amsterdam, 1967.

12. Byberg, J. R. Chem Phys Lett 1973, 23, 414.

13. Dalgard, E.; Linderberg, J. J Chem Phys 1976, 65, 692.

14. Varandas, A. J. C. Chem Phys Chem 2002, 3, 433.

15. Engdahl, A.; Nelander, B. J Chem Phys 2005, 122, 126101.

16. Varandas, A. J. C.; Pais, A. A. C. C.; Marques, J. M. C.; Wang, Y. Chem Phys Lett 1996, 249, 264.

17. VENUS96: Hase, W. L.; Duchovic, R. J.; Hu, X.; Komornik, A.; Lim, K. F.; Lu, D.-H.; Peslherbe, G. H.; Swamy, K. N.; van de Linde, S. R.; Varandas, A. J. C.; Wang, H.; Wolf, R. J. QCPE Bull 1996, 16, 43.

18. Varandas, A. J. C.; Brandão, J.; Pastrana, M. R. J Chem Phys 1992, 96, 5137.

19. Varandas, A. J. C. Chem Phys Chem 2005, 6, 453.

20. Varandas, A. J. C.; Llanio-Trujillo, J. L. J Theor Comp Chem 2002, 1, 31.

21. Clyne, M. A. A.; Watson, R. T. J Chem Soc Faraday Trans 1 1974, 70, 2250.

22. Clyne, M. A. A.; Nip, W. S. J Chem Soc Faraday Trans 2 1976, 72, 838.

23. Kurylo, M. J.; Braun, W. Chem Phys Lett 1976, 37, 232.

24. Zahniser, M. S.; Kaufman, F.; Anderson, J. G. Chem Phys Lett 1976, 37, 226.

25. Varandas, A. J. C.; Caridade, P. J. S. B.; Zhang, J. Z. H.; Cui, Q.; Han, K. L. J Chem Phys 2006, 125, 064312. 